\title{
Perancangan Perangkat Lunak Kompresi Citra Menggunakan Transformasi Wavelet dan PCA
}

\author{
Andrian \\ Politeknik Negeri Media Kreatif PSDD Medan, Medan, Indonesia \\ Email : wonderguy3011@gmail.com
}

\begin{abstract}
Abstrak
Tingginya kebutuhan citra digital sekarang ini dipengaruhi oleh keinginan masyarakat yang selalu mengabadikan momen hidup kedalam suatu citra digital. Citra digital yang baik memiliki filesize yang besar, sehingga membutuhkan ruang media penyimpanan yang lebih besar untuk menyimpan lebih banyak gambar. Ada teknik pengolahan citra yang dapat memperkecil filesize adalah teknik kompresi. Dengan menggabungkan metode tranformasi wavelet dan Principal Component Analysis pada sebuah perancangan aplikasi dapat menghasilkan teknik kompresi yang baik.
\end{abstract}

Abstract

Now days, The most needed of digital images is influenced by the people will that want to take a part of moment life into digital image. The good digital image has the big filesize, so it will need more space memory to saving more images. There is technique in image processing to decrease file size that is compression. By combine wavelet transformation method and Principal Component Analysis in developing application can produce the good compression technique.

\section{PENDAHULUAN}

Kebutuhan masyarakat terhadap suatu citra digital sekarang ini sangat tinggi. Hampir setiap momen penting yang terjadi pada masyarakat ingin diabadikan dalam suatu citra digital. Sayangnya, untuk menghasilkan citra digital yang berkualitas tinggi dibutuhkan media penyimpanan yang besar agar dapat menampung banyak data citra digital. Untuk itu, dibutuhkan suatu aplikasi yang dapat mengecilkan ukuran (mengkompresi) citra sekecil mungkin dengan menerapkan algoritma Transformasi wavelet dan Principal Component Analysis (PCA).

Proses kompresi dilakukan menggunakan metode wavelet. Jenis filter induk yang akan digunakan adalah haar (daubechies 2), daubechies 4 dan daubechies 6. Langkah - langkah proses pengkompressan citra adalah sebagai berikut, transformasi wavelet diskrit yaitu mendekomposisi citra inputan dengan menggunakan algoritma piramida. Kemudian hasil dekomposisi (koefisien wavelet) akan dijadikan inputan untuk mencari feature component dalam proses principal component analysis. Feature component dari proses principal Component analysis akan digunakan dalam proses kuantisasi yang merupakan proses mengurangi tingkat keabua - abuan warna sehingga akan terjadi pengurangan nilai tingkat keabuan - abuan yang tidak seragam. Setelah dilakukan proses kuantisasi, maka dilakukan proses transformasi wavelet invers ( proses rekonstruksi ) terhadap matriks tersebut, dihasilkan nilai untuk citra output ( hasil kompresi ). Proses diatas memanfaatkan dua buah fungsi filter, yaitu low-pass filter ( scalling function ) dan high-pass filter ( wavelet function). 


\section{LANDASAN TEORI}

\section{a. Citra}

Secara harfiah, citra (image) adalah gambar pada bidang dwimatra (dua dimensi). Ditinjau dari sudut pandang matematis, citra merupakan fungsi menerus (continue) dari intensitas cahaya pada bidang dwimatra. Sumber cahaya menerangi objek, objek memantulkan kembali sebagian dari berkas cahaya tersebut. Pantulan cahaya ini ditangkap oleh oleh alat-alat optik, misalnya mata pada manusia, kamera, pemindai (scanner), dan sebagainya, sehingga bayangan objek yang disebut citra tersebut terekam.

Secara umum dan sederhana, citra dapat didefinisikan sebagai representasi visual dari suatu objek. Lebih jauh lagi, citra juga dapat diartikan sebagai gambaran yang representatif mengenai suatu objek yang sedemikian sehingga citra tersebut dapat memberikan kesan yang mendalam mengenai objek yang dimaksud. Jika ingin mendefinisikannya lebih bebas lagi, citra dapat didefinisikan sebagai bentuk visual yang dapat diterima secara baik oleh indera penglihatan, apapun bentuknya. Dalam bidang komputer, citra atau disebut juga image merupakan representasi visual dari suatu objek setelah mengalami berbagai transformasi data dari berbagai bentuk rangkaian numerik.

\section{b. Pengolahan Citra}

Pengolahan citra merupakan sebuah bentuk pemrosesan sebuah citra atau gambar dengan cara memproses numerik dari gambar tersebut, dalam hal ini yang diproses adalah masing - masing pixel atau titik dari gambar tersebut.

Meskipun sebuah citra kaya informasi, namun seringkali citra yang kita miliki mengalami penurunan mutu (degradasi), misalnya mengandung cacat atau derau (noise), warnanya terlalu kontras, kurang tajam, kabur (blurring), dan sebagainya. Tentu saja citra semacam ini menjadi lebih sulit diinterpretasi karena informasi yang disampaikan oleh citra tersebut menjadi berkurang. Agar citra yang mengalami gangguan mudah diinterpretasi ( baik oleh manusia maupun mesin), maka citra tersebut perlu dimanipulasi menjadi citra lain yang kualitasnya lebih baik.

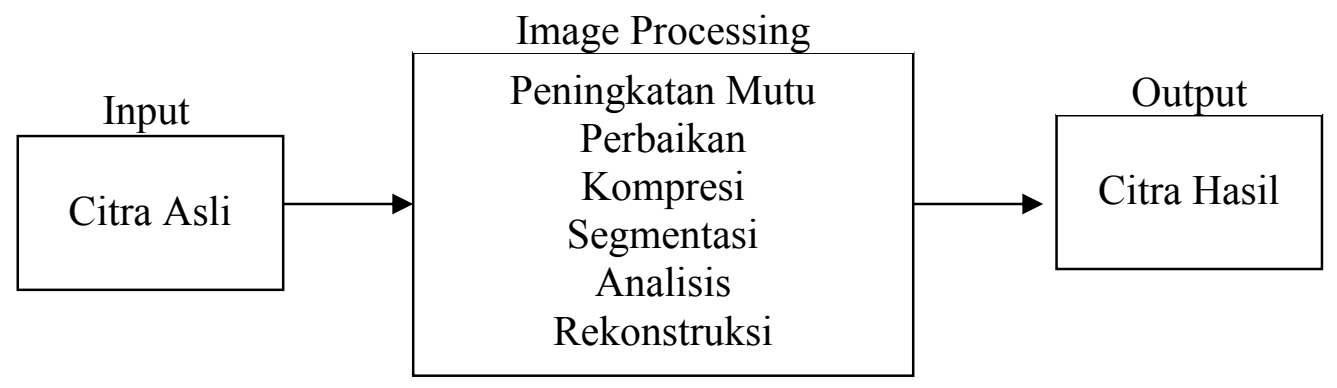

\section{c. Kompresi Citra}

Gambar 1. Proses Pengolahan Citra

Kompresi citra (image compression) adalah proses untuk meminimalkan jumlah bit yang merepresentasikan suatu citra sehingga ukuran citra menjadi lebih kecil. Pada dasarnya teknik kompresi citra digunakan untuk proses transmisi data (datatransmission) dan penyimpanan data (storage). Ada dua teknik kompresi citra yaitu :

\section{a. Loseless Compression}

Lossless data kompresi adalah kelas dari algoritma data kompresi yang memungkinkan data yang asli dapat disusun kembali dari data kompresi. Lossless data 
kompresi digunakan dalam berbagai aplikasi seperti format ZIP dan GZIP. Lossless juga sering digunakan sebagai komponen dalam teknologi kompresi data lossy. Kompresi Lossless digunakan ketika sesuatu yang penting pada kondisi asli. Beberapa format gambar seperti PNG atau GIF hanya menggunakan kompresi lossless, sedangkan yang lainnya sperti TIFF dan MNG dapat menggunakan metode lossy atau lossless.

\section{b. Lossy Compression}

Lossy kompresi adalah suatu metode untuk mengkompresi data dan mendekompresinya, data yang diperoleh mungkin berbeda dari yang aslinya tetapi cukup dekat perbedaaanya. Lossy kompresi ini paling sering digunakan untuk kompres data multimedia (Audio, gambar diam). Format kompresi lossy mengalami generation loss yaitu jika melakukan berulang kali kompresi dan dekompresi file akan menyebabkan kehilangan kualitas secara progresif. Contoh metode lossy adalah metode CS\&Q (coarser sampling and/or quantization), JPEG, dan MPEG.

\section{d. Transformasi Wavelet}

Transformasi wavelet menghasilkan sejumlah sub citra yang terdiri dari citra pendek dan citra detil. Pengembangan untuk kasus sinyal berdimensi 2-D (sinyal citra 2-D), biasanya dilakukan dengan menerapkan bank filter secara terpisah terhadap sinyal citra. Bisanya digunakan sebuah Low-pass dan High-pass. Perkalian matriks citra dengan matriks low-pass-filter menghasilkan sinyal yang biasa disebut dengan citra pendekatan (approximation image), dan perkalian matriks citra dengan high-pass-filter pada arah spesifik menghasilkan citra detil (details image).

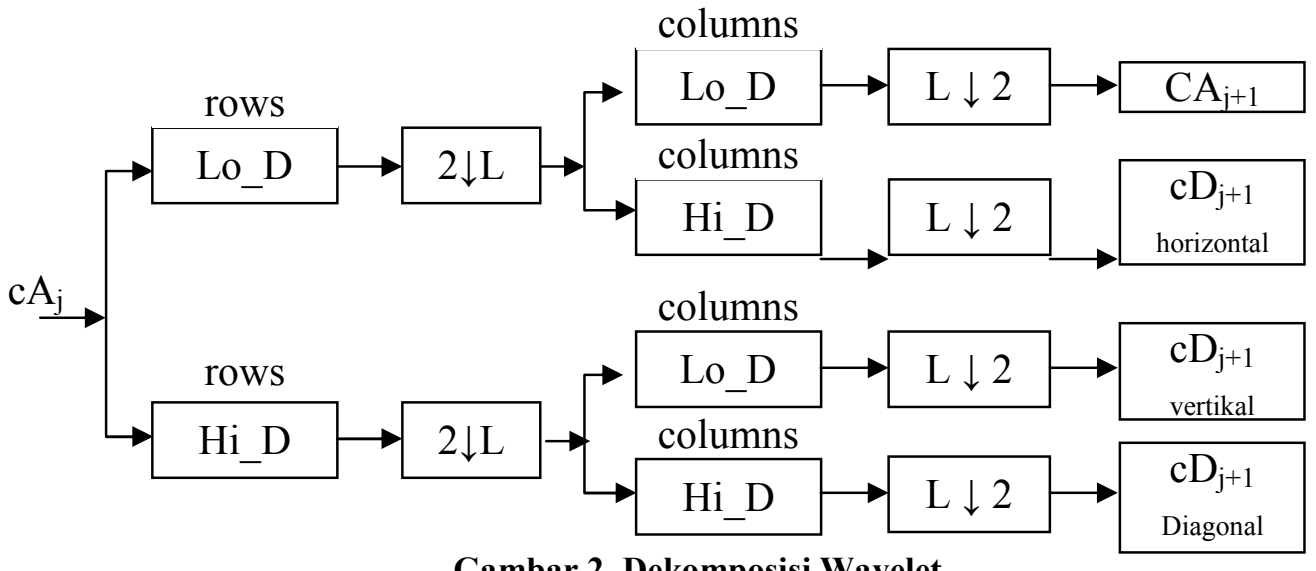

Gambar 2. Dekomposisi Wavelet

Keterangan :

$\mathrm{Lo}=$ low Pass filter

$\mathrm{Hi}=$ High pass filter

$\downarrow 2=$ downsampling dengan faktor 2 sub band :

LL : Aproksimaksi (Ap)

HL : detail Horizontal (detil 1)

LH : detail Vertikal ( detail 2)

HH : Detail Diagonal (detil 3) 


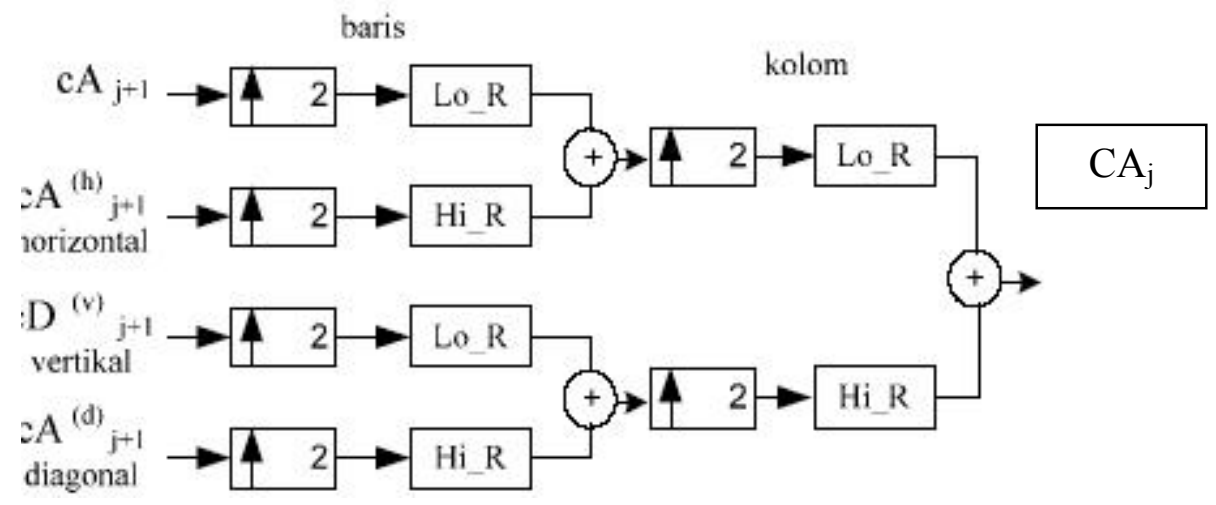

Keterangan :

Gambar 3 Rekonstruksi Wavelet

$\mathrm{Lo}=$ low Pass filter

$\mathrm{Hi}=$ High pass filter

$\uparrow 2=$ up sampling dengan faktor 2 sub band :

LL : Aproksimaksi (Ap)

HL : detail Horizontal (detil 1)

LH : detail Vertikal ( detail 2)

$\mathrm{HH}$ : Detail Diagonal ( detil 3)

\section{e.Principal Component Analysis (PCA)}

PCA diciptakan pada 1901 oleh Karl Pearson. Sekarang ini kebanyakandigunakan sebagai alat dalam analisis data eksplorasi dan untuk membuat model prediksi. PCA melibatkan perhitungan dekomposisi eigenvalue dari data matriks kovarians atau dekomposisi nilai singular dari matriks data, biasanya setelahketerpusatan berarti data untuk setiap atribut. Hasil PCA biasanya dibahas dalam hal skor komponen dan loadings (Shaw, 2003).

\section{Proses Pencarian Feature Component}

Principal Component Analysis( PCA ) digunakan untuk mereduksi dimensi dari sekumpulan atau ruang gambar sehingga basis atau sistem koordinat yang baru dapat menggambarkan mode yang khas dari sekumpulan tersebut dengan lebih baik. Sasaran dari Principal Component Analysis adalah untuk menangkap variasi total di dalam gambar yang dilatihkan, dan untuk menjelaskan variasi ini dengan sedikit variabel yang sedikit. Prinsip dasar dari algoritma PCA adalah mengurangi dimensi suatu set data namun tetap mempertahankan sebanyak mungkin informasi dalam set data tersebut. Secara matematis PCA mentransformasikan sejumlah variabel yang berkorelasi ke dalam bentuk yang bebas tidak berkorelasi

\section{Algoritma PCA adalah sebagai berikut :}

1. Mencari komponen rata-rata dari matrik X yang dirumuskan dengan persamaan berikut: 


$$
\overline{x_{1}}=\frac{1}{n} \sum_{k=1}^{n} x_{1, k}
$$

sehingga dimensi dara rata-rata citra tersebut adalah $1 x N$. Dan zero mean dari citra dapat dihitung dengan mengurangkan nilai masing-masing intensitas citra dengan rata-rata seluruh citra, seperti terlihat pada Persamaan

$\mathrm{C}=\left(\mathrm{X}_{\mathrm{i} . \mathrm{j}}-\mu_{\mathrm{j}}\right)\left(\mathrm{X}_{\mathrm{i} . \mathrm{j}}-\mu_{\mathrm{j}}\right)^{\mathrm{T}}$

2. Mencari matrik covariance dengancmenggunakan persamaan berikut:

$$
C=X^{*} X^{T}
$$

3. Mencari eigenvalue dan eigenvector dari matrik covariance dengan menggunakan persamaan berikut:

$$
\begin{aligned}
& C Q=\lambda Q \\
& C Q=\lambda I Q \text { dan } \\
& (\lambda I-A) Q=0 \\
& \operatorname{Det}(\lambda I-A)=0 \\
& \text { dimana } \lambda \text { adalah eigenvalue dan } Q \text { adalah eigenvector. }
\end{aligned}
$$

4. Mencari Feature Principal Component dengan mentransformasi data set ke dalam ruang eigen dengan menggunakan persamaan

$f=\sum_{i=1}^{m} Q *\left(X_{i}-\overline{x_{l}}\right)$

imenyatakan data ke-i, $\mathrm{m}$ adalah jumlah data dan $\mathrm{Q}$ menyatakan matriks eigenvector).

\section{f. Metode Pengukuran Hasil Kompresi}

1. Signal to Noise Ratio

Signal-to-noise ratio (sering disingkat SNR atau $\mathbf{S} / \mathbf{N}$ ) adalah ukuran yang digunakan dalam sains dan teknik untuk mengukur berapa banyak sinyal telah rusak oleh noise. Hal ini didefinisikan sebagai perbandingan kekuatan sinyal noise merusak kekuatan sinyal. Sebuah rasio yang lebih tinggi daripada 1:1 menunjukkan sinyal dari kebisingan. Sementara SNR umumnya dikutip untuk sinyal-sinyal listrik, dapat diterapkan pada segala bentuk sinyal (seperti tingkat isotop dalam inti es atau biokimia sinyal antara sel-sel). Rumusan untuk mencari Signal to Noise Ratio.

$$
S N R_{d B}=10 \log _{10}\left(\frac{A_{\text {signal }}}{A_{\text {noise }}}\right)^{2}=20 \log _{10}\left(\frac{A_{\text {signal }}}{A_{\text {noise }}}\right)
$$

\section{Peak Signal to Noise Ratio}

ungkapan Peak signal-to-noise ratio, sering disingkat PSNR, adalah istilah teknis untuk rasio antara daya maksimum yang mungkin dari suatu sinyal dan merusak kekuatan suara yang mempengaruhi kesetiaan dari perwakilan. Karena banyak sinyal yang sangat luas rentang dinamis, PSNR biasanya dinyatakan dalam bentuk logaritmikdesibel skala.

Hal ini paling mudah didefinisikan melalui mean kuadrat kesalahan(MSE) yang selama dua $m \times n$ monokrom gambar aku dan $K$ di mana salah satu gambar dianggap sebagai perkiraan yang bising yang lain didefinisikan sebagai berikut :

$$
M S E=\frac{1}{m n} \sum_{i=0}^{m-1} \sum_{j=0}^{n-1}[I(i, j)-K(i, j)]^{2}
$$

Yang PSNR didefinisikan sebagai : 


$$
\begin{aligned}
P S N R & =10 \cdot \log _{10}\left(\frac{M A X_{I}^{2}}{M S E}\right) \\
& =20 \cdot \log _{10}\left(\frac{M A X_{I}}{\sqrt{M S E}}\right)
\end{aligned}
$$

\section{Implementasi Metode Transformasi Wavelet dan PCA untuk Kompresi Citra}

1. Citra Inputan (Citra Asli )

2. Proses Padding Untuk melakukan proses transformasi wavelet dimensi citra harus berukuran $2^{\mathrm{n}} \mathrm{x}$ $2^{\mathrm{n}}$. Untuk itu, bila dimensi citra tidak sesuai dengan $2^{\mathrm{n}} \times 2^{\mathrm{n}}$ maka akan dilakukan proses padding terhadap dimensi citra ke dimensi yang terdekat yang sesuai dengan $2^{\mathrm{n}}$. Padding adalah suatu proses perbesaran dimensi citra. Padding dapat dilakukan dengan menggunakan rumussebagai berikut :

$$
d=2^{2} \log (\text { width })+1
$$

3. Proses Pembentukan Filter (LPF dan HPF)

Pembentukan filter dilakukan dengan melihat dimensi citra terlebih dahulu. Besar filter adalah width $\mathrm{x}$ (height/2). Berikut ini adalah dilakukan pembentukan filter daubechies 2 terhadap citra $\mathrm{A}$

- Low pass filter

$$
\operatorname{lpf}=\left[\begin{array}{cccc}
0,5 & 0,5 & 0 & 0 \\
0 & 0 & 0,50,5
\end{array}\right]
$$

- High pass filter

$$
l p f=\left[\begin{array}{cccc}
0,5 & -0,5 & 0 & 0 \\
0 & 0 & 0,5-0,5
\end{array}\right]
$$

4. Proses Dekomposisi

Transformasi wavelet diskrit secara umum merupakan dekomposisi citra pada frekuensi sub band citra tersebut. komponen sub band transformasi wavelet dihasilkan dengan cara penurunan level dekomposisi

$$
\begin{aligned}
& \text { LL }=\left(\operatorname{lpf} *(\operatorname{lpf} * \text { image })^{\mathrm{T}}\right)^{\mathrm{T}} \\
& \mathrm{HL}=\left(\operatorname{lpf} *(\operatorname{hpf} * \text { image })^{\mathrm{T}}\right)^{\mathrm{T}} \\
& \mathrm{LH}=\left(\mathrm{hpf} *(\operatorname{lpf} * \text { image })^{\mathrm{T}}\right)^{\mathrm{T}} \\
& \mathrm{HH}=\left(\operatorname{hpf} *(\operatorname{hpf} * \text { image })^{\mathrm{T}}\right)^{\mathrm{T}}
\end{aligned}
$$

5. Proses pembentukan Feature Component PCA

Principal Component Analysis( PCA ) digunakan untuk mereduksi dimensi dari sekumpulan atau ruang gambar sehingga basis atau sistem koordinat yang baru dapat menggambarkan mode yang khas dari sekumpulan tersebut dengan lebih baik.

6. Proses pengurangan derajat keabu - abuan ( Kuantisasi )

Proses pengurangan derajat keabua - abuan (kuantisasi) berfungsi untuk mengurangi kedalaman bit depth nilai keabuan - abuan suatu warna citra. 
7. Proses Rekonstruksi Citra

Proses rekonstruksi merupakan proses pembentukan kembali ke empat sub band citra menjadi ke bentuk semula. Sebelum rekonstruksi citra dilakukan, ke empat sub band harus sudah mengalami proses kuantisasi agar ukuran citra yang dihasilkan lebih kecil dari citra aslinya.

\section{Implementasi dan Pengujian}

Adapun pengujian kompresi citra pada sebuah gambar seperti pada contoh dibawah.

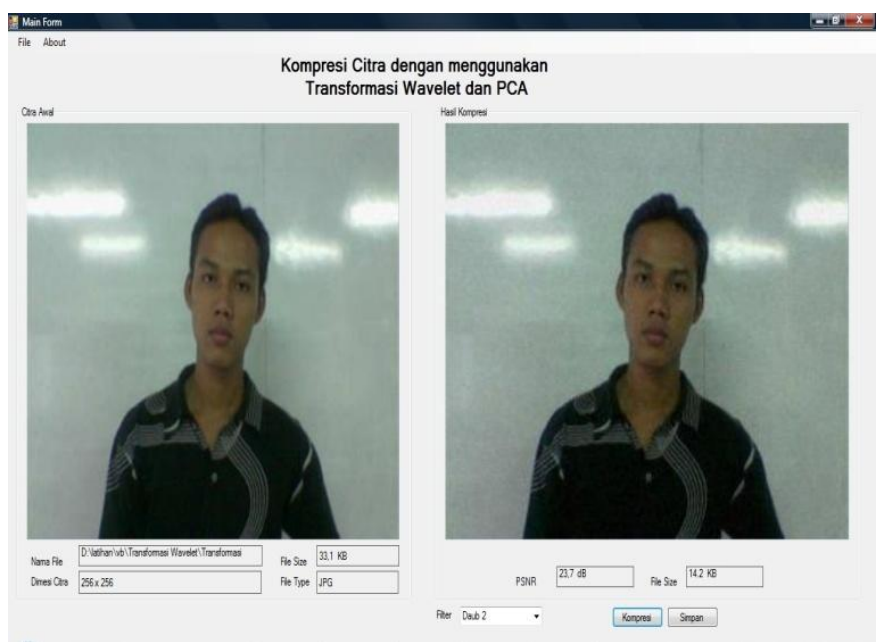

Gambar 5. Proses Kompresi Citra

Pada contoh kompresi citra pada gambar 5 diatas, images memiliki filename transformasi.jpp dengan filesize awal 33.1 KB dengan resolusi gambar 256 x 256 Pixel. Setelah dilakukan kompresi citra dengan memilih filter Daubicies 2, maka didapatkan hasil kompresi dengan filesize menjadi 14,2 KB dan PSNR sebesar 23,7 dB yang artinya tidak terlalu berbeda dengan gambar aslinya.

\section{Kesimpulan}

Adapun simpulan yang dapat diambil pada pengujian adalah

1. Tranformasi wavelet baik digunakan untuk proses kompresi citra. Namun dengan menggabungkan metode tranformasi wavelet dengan Principal Component Analysis dapat menyebabkan tingginya perbedaan dengan citra Aslinya.

2. Terkadang resolusi image juga mempengaruhi terjadinya penambahan size karena akan dilakukan proses padding jika resolusi image tidak memenuhi syarat $2^{\text {n }}$

\section{DAFTAR PUSTAKA}

1. Russ, J.C., 2002, "The Image Processing Handbook", CRC Press LLC.

2. Simarmata, J. 2006, "Pengenalan Teknologi Komputer dan Informasi", Andi Offset, Yogyakarta.

3. Kompresi Citra Rgb Dengan Metode Kuantisasi, http://p3m.amikom.ac.id /p3m/dasi/maret08/09 - AMIKOM_Yogyakarta KOMPRESI CITRA RGB 20DENGAN.pdf,

4. Kompresi Citra Gray Scale Dengan Modifikasi Algoritma Kuantisasi, http://p3m.amikom.ac.id/p3m/dasi/des07/05 - AMIKOM_Yogyakarta _KOMPRESI CITRA GRAY SCALE DENGAN MODIFIKASI.pdf. 
ALGORITMA: Jurnal IImu Komputer dan Informatika

Volume: 03, Number: 01, April 2019 ISSN 2598-6341 (online)

5. Principal Component Analysis (Pca) Sebagai Salah Satu Metode Untuk Mengatasi Masalah Multikolinearitas, http://student.eepis- its.edu/ memelz/pca.html,.

6. Pengantar Pengolahan Citra, http://webmail.informatika.org/ rinaldi /Buku/Pengolahan Citra Digital/ Bab-1 Pengantar Pengolahan Citra.pdf.

7. Implementasi Alihragam Wavelet untuk Pemampatan Data Citra, http://eprints.ums.ac.id/776/1/Emitor_HNS_ImpelementasiAlihRagamWavelet.p df.

8. PCA Colour Image Compression Using Vector Quantization, http://www.gisdevelopment.net/aars/acrs/1999/ps5/ps5072.asp. 